\title{
DUSP1 enhances the chemoresistance of gallbladder cancer via the modulation of the p38 pathway and DNA damage/repair system
}

\author{
JUN FANG, ZHIMIN YE, FEIYING GU, MAOHUI YAN, QINGREN LIN, JUAN LIN, \\ ZHUN WANG, YAPING XU and YUEZHEN WANG \\ Department of Radiation Oncology, Zhejiang Province Cancer Hospital, Hangzhou, Zhejiang 310022, P.R. China
}

Received July 25, 2016; Accepted November 21, 2017

DOI: $10.3892 / \mathrm{ol} .2018 .8822$

\begin{abstract}
Cisplatin (CDDP) is a commonly used drug for gallbladder cancer (GBC) chemotherapy. However, resistance to CDDP treatment results in relapse. Therefore, there is a need for the development of more effective treatment strategies to overcome chemoresistance. Dual-specificity phosphatase 1 (DUSP1) was reported to be involved in the resistance of a number of chemotherapeutic agents and was revealed to be highly expressed in CDDP-resistant GBC cells and CDDP-treated tumor types compared with normal cells or tissues in the present study. DUSP1 was revealed to inhibit the cytotoxicity of CDDP in two GBC cell lines, SGC996 and GBC-SD. P38 mitogen-activated protein kinases may be involved in the mechanism of chemoresistance. Furthermore, the number of DNA double-strand breaks in SGC996 OE cells was reduced compared with SGC996 vector cells indicating DUSP1 may attenuate the chemotherapeutic efficiency. Due to its potency against CDDP treatment, DUSP1 may be a promising target to overcome chemoresistance in GBC therapy.
\end{abstract}

\section{Introduction}

Gallbladder cancer (GBC) has a high occurrence among populations in the Andean area, Native Americans and Mexican Americans (1). GBC is often diagnosed at a late stage due to its unapparent symptoms at the early stage (2). Surgery is currently the primary option for GBC treatment alongside a combination of 5-fluorouracil (5-FU) and cisplatin (CDDP), which is a common choice for advanced $\operatorname{GBC}(3,4)$. Although

Correspondence to: Dr Yuezhen Wang, Department of Radiation Oncology, Zhejiang Province Cancer Hospital, 38 Guangji Road, Hangzhou, Zhejiang 310022, P.R. China

E-mail: wangyuezhen88@126.com

Abbreviations: GBC, gallbladder cancer; DUSP1, dual-specificity phosphatase 1; CDDP, cisplatin; DSB, double-strand breaks

Key words: dual-specificity phosphatase 1, gallbladder cancer, chemo-resistance, DNA damage/repair chemotherapy exerts a therapeutic effect in a number of patients, chemoresistance eventually occurs in patients that receive chemotherapy (5).

CDDP is one of the most widely used cytotoxic anticancer drugs (6-9). CDDP mainly reacts with the N7-position of guanine, forming inter- and intra-strand DNA cross-links and blocks replication and transcription, and may result in replication-mediated double-strand breaks (DSBs) $(10,11)$. However, resistance to these drugs undermines their curative potential. The resistance to CDDP and numerous other chemotherapeutic agents is partially due to a wide range of genetic and epigenetic alterations which result in abnormal cell survival (12-14). In the present study, the expression of a number of chemotherapy resistance-associated genes (DUSP1, HIF-1 $\alpha$, MDR1, MRP1) was compared between CDDP-resistant SGC996 and GBC-SD cells and normal SGC996 and GBC-SD cells. Notably, one gene (dual-specificity phosphatase 1 (DUSP1)) expression was markedly increased in the established CDDP-resistant cells compared with the normal cells. Using an in vivo assay, DUSP1 expression in subcutaneous tumors was also elevated following CDDP treatment.

DUSP1 is one member of the DUSP family, which consists of a total of 25 members. The expression of DUSP1 is cancer-dependent (15). In a range of epithelial tumor types including pancreatic ductal adenocarcinoma (PDAC), non-small-cell lung cancer, breast, ovarian, gastric and early-stage prostate cancer, DUSP1 was revealed to be overexpressed, however it was decreased in hepatocellular carcinoma (16-19). The DUSP family are specific inhibitory molecules which target mitogen-activated protein kinases (MAPKs) (20). By inhibiting p38 and c-Jun N-terminal kinase (JNK) activity, DUSP1 enhances resistance to doxorubicin or paclitaxel in breast cancer, osteosarcoma and non-small cell lung carcinoma cell lines $(17,21-24)$. However, there are few studies on the association between DUSP1 expression and chemoresistance in GBC.

The present study examined the expression of DUSP1 in two GBC cell lines: SGC996 and GBC-SD. DUSP1 expression was revealed to be relatively low in GBC cells and was overexpressed in the two cell lines. An MTS assay revealed that DUSP1 overexpressing GBC cells had better survival and lower apoptosis following CDDP treatment compared with untreated control cells. DUSP1 overexpression was verified to inhibit p38 MAPK activity and decrease apoptosis compared 
with control cells. Further experiments indicated that fewer DSB were formed in DUSP1 overexpressing cells compared with control cells. Therefore, DUSP1 may be a potential therapeutic target to enhance the efficiency of chemotherapy for GBC.

\section{Materials and methods}

Cell culture. Human GBC cell line GBC-SD and SGC996 cells were obtained from the Type Culture Collection of the Chinese Academy of Sciences (Shanghai, China). GBC-SD and SGC996 were cultured in RPMI-1640 (Gibco; Thermo Fisher Scientific, Inc, Waltham, MA, USA) containing penicillin $(100 \mathrm{IU} / \mathrm{ml})$ and streptomycin $(100 \mu \mathrm{g} / \mathrm{ml})$, supplemented with $10 \%$ fetal bovine serum which was diluted in PBS (Gibco; Thermo Fisher Scientific, Inc.). All cell lines were cultured in a $5 \%(\mathrm{v} / \mathrm{v}) \mathrm{CO}_{2}$ humidified incubator at $37^{\circ} \mathrm{C}$.

Construction of stable expression $G B C$ cell lines. DUSP1 expression plasmid was generated by cloning DUSP1 cDNA into the basic retroviral transfer plasmid Pwpi (Biovector Science Lab, Inc., Beijing, China) to generate the plasmid pWPI-DUSP1. To generate DUSP1 overexpressing cells, GBC-SD and SGC996 cells were transfected with lentiviral vectors pWPI-DUSP1 or pWPI-Vec, the psAX2 packaging plasmid and the pMD2G envelope plasmid were used to obtain the lentivirus at $37^{\circ} \mathrm{C}$. This was then collected and frozen at $-80^{\circ} \mathrm{C}$ until use. The cells were transfected using Lipofectamine ${ }^{\circledR} 2000$ (Invitrogen; Thermo Fisher Scientific, Inc.). Lentiviral supernatants were then collected to infect GBC cells. Following viral infection, the media was replaced with normal RPMI-1640 culture media. The stable cells were selected and examined using reverse transcription-quantitative polymerase chain reaction (RT-qPCR) and western blot analysis.

$R T-q P C R$. For RNA extraction, total RNA was isolated using Trizol reagent (Invitrogen; Thermo Fisher Scientific, Inc.). A total of 1-2 $\mu \mathrm{g}$ of total RNA was subject to RT using Superscript III transcriptase (Invitrogen; Thermo Fisher Scientific, Inc.). RT-qPCR was conducted using a Bio-Rad CFX96 system (Bio-Rad, Laboratories, Inc., Hercules, CA, USA) with SYBR green to determine the mRNA expression level of a gene of interest such as DUSP1, HIF-1 $\alpha$, MDR1 and MRP1. Expression levels were normalized to the expression of GAPDH mRNA. In brief, 50 ng small RNA was processed for poly A addition by adding 1 unit of polymerase with $1 \mathrm{mM}$ ATP in $1 \times R T$ buffer (Invitrogen; Thermo Fisher Scientific, Inc.) at $37^{\circ} \mathrm{C}$ for $10 \mathrm{~min}$ in a $10 \mu 1$ volume, and then heat inactivated at $95^{\circ} \mathrm{C}$ for $2 \mathrm{~min}$, and then $50 \mathrm{pmol}$ anchor primer (DUSP1, HIF-1 $\alpha$, MDR1 and MRP1) were added to $12.5 \mu 1$ volume total PCR mix, incubated at $65^{\circ} \mathrm{C}$ for $5 \mathrm{~min}$, and the last step was cDNA synthesis, with the addition of $2 \mu \mathrm{l} 5 \mathrm{X}$ RT buffer, $2 \mu 110 \mathrm{mM}$ dNTP and $1 \mu \mathrm{l}$ reverse transcriptase to a total volume of $20 \mu \mathrm{l}$ and incubated at $42^{\circ} \mathrm{C}$ for $1 \mathrm{~h} 25 \mathrm{~min}$. The sequences of the GAPDH primers are as follows: Forward, 5'-GGAGTCAAC GGATTTGGT-3' and reverse, 5'-GTGATGGGATTTCCA TTGAT-3'. The sequences of DUSP1 are as follows: Forward, 5'-CCTGACAGCGCGGAATCT-3' and reverse, 5'-GATTTC CACCGGGCCAC-3'. Analysis of relative gene expression was quantified with the $2^{-\Delta \Delta C q}$ method (25).
Western blot analysis. Cells were lysed in RIPA buffer (Beyotime Institute of Biotechnology, Haimen, China) and proteins $[20-50 \mu \mathrm{g}$, determined by a BCA Protein Assay kit (Thermo Fisher Scientific, Inc.)] were separated on a $10 \%$ gel using SDS-PAGE and then transferred onto polyvinylidene fluoride membranes (EMD Millipore, Billerica, MA, USA). Membranes were blocked with $5 \%$ bovine serum albumin at room temperature for $2 \mathrm{~h}$ and incubated with specific primary antibodies at room temperature for $1 \mathrm{~h}(1: 1,000$ in 0.5\% FBS) against GAPDH (cat no. G8795; Sigma-Aldrich, Merck KGaA, Darmstadt, Germany), Caspase-3 (active; cat no. 1476-1; Epitomics; Abcam, Cambridge, UK), poly (ADP-ribose) polymerase (PARP; cat no. 9542; Cell Signaling Technology, Inc., Danvers, MA, USA), phosphorylated-H2A histone family $(\gamma \mathrm{H} 2 \mathrm{AX}$; cat no. JBW301; EMD Millipore) and phospho (p)-p38 (cat no. 4822; Abcam). The blots were incubated with horseradish peroxidase-conjugated secondary antibodies at room temperature for $1 \mathrm{~h}$ (including goat anti-rabbit IgG (cat no. 7054; dilution, 1:10,000; Cell Signaling Technology, Inc., Danvers, MA, USA) and goat anti-mouse IgG (cat no. 7056; dilution, 1:10,000; Cell Signaling Technology, Inc.) and visualized using the electrochemiluminesence system Image Lab V4.0 (Bio-Rad Laboratories, Inc.).

MTS assay. Stable transfected cells $\left(5 \times 10^{3}\right)$ were seeded on a 96-well plate with 3 replicate wells. Following cell adhesion, various concentrations of CDDP (Sigma-Aldrich, Merck $\mathrm{KGaA})$ diluted in DMSO $(1,1.5,2,2.5,3,3.5 \mu \mathrm{g} / \mathrm{ml})$ were added. Following incubation for $1 \mathrm{~h}$ at $37^{\circ} \mathrm{C}$, cell viability was assessed every $48 \mathrm{~h}$ utilizing the tetrazolium-based MTT colorimetric assay (CellTiter 96 cell proliferation assay kit; Promega Corporation, Madison, WI, USA) according to the manufacturer's protocol. All experiments were performed at least in triplicate on three separate occasions. A dose-response curve was plotted.

Apoptosis assay. Cell apoptosis was evaluated using a flow cytometry assay. Briefly, (1x105 SGC996 cells and $2 \times 10^{4}$ GBC-SD cells) Vector and OE cells seeded in 6-well plates were harvested and washed twice using phosphate buffered saline, stained with propidium iodide (PI) in binding buffer (BD Biosciences, San Jose, CA, USA) subsequent to 15 min incubation at room temperature in darkness, and detected by Becton-Dickinson FACS Calibur FCM using the software within the system (BD Biosciences).

Subcutaneous xenograft model. All experimental procedures were conducted in accordance with the institutional guidelines for the care and use of laboratory animals (26), and ethical approval was provided by the Institutional Animal Care and Use Committee of Zhejiang Medical College, Zhejiang University (Zhejiang, China) for all animal experiments. Animals were subjected to isoflurane anesthesia. Animal studies were conducted using female 5-week-old nude mouse (20-30 g) from Silaike Experimental Animal Co. Ltd. (Shanghai China). A total of 8 mice were housed in a specific pathogen-free laboratory, airconditioned, with a $12 / 12 \mathrm{~h} \mathrm{light/dark}$ cycle. Subcutaneous implantation was performed as previously described (27) where mice 
were injected subcutaneously with DUSP1-Vector or DUSP1-OE SGC996 cells. A total of $1 \times 10^{6}$ SGC996 stable cells (mixed with Matrigel in a ratio of 1:1) were injected subcutaneously. After 1 week, mice were randomized into two groups: Mice treated with CDDP solution at a dose of $0.5 \mathrm{mg} / \mathrm{kg}$ in the treatment group (the $\mathrm{CDDP}(+)$ group) every 4 days for 3 weeks and the control group [CDDP(-) group treated with DMSO]. The mice were sacrificed under the influence of Fluothane on the 21st day before they lost $40 \%$ weight and tumor tissue was used to extract total tissue protein. DUSP1 expression was detected using western blot analysis.

Statistical analysis. Data are expressed as mean \pm standard error of the mean of at least 3 independent experiments. Statistical analyses were performed using a paired Student's t-test using SPSS 17.0 (SPSS, Inc., Chicago, IL, USA). $\mathrm{P}<0.01$ was considered to indicate a statistically significant difference.

\section{Results}

DUSP1 expression was markedly increased in the CDDP-resistant SGC996 cell lines and CDDP-treated subcutaneous tumor types. In order to explore the genes involved in GBC chemoresistance, a CDDP-resistant SGC996 cell line was established. Genes such as BCRP, MRP1, MDR1 and HIF1 were previously reported to be associated with drug-resistance in various cancer types were detected (28-30). DUSP1 expression was substantially elevated in the CDDP-resistant SGC996 cells compared with the normal SGC996 cells (Fig. 1A). DUSP1 was reported to be involved in gemcitabine-resistance in PDAC (31). However, the association between the induction of DUSP1 and CDDP-resistance in GBC remains unclear. In order to further confirm the DUSP1 induction resulting from CDDP treatment in vivo, subcutaneous xenograft GBC mouse models were generated by transplanting normal SGC996 cells into nude mice. The nude mice were divided into two groups: A control tumor group and a CDDP-treated group. As presented in Fig. 1B, DUSP1 expression was increased in the CDDP-treated group compared with the control group.

Altogether, the results presented in Fig. 1A and B reveal that DUSP1 expression is higher in CDDP-resistant cell lines and CDDP-treated tumors, suggesting that DUSP1 expression may be associated with CDDP-resistance.

DUSP1 overexpression resulted in enhanced chemoresistance in SGC996 and GBC-SD cells. To further confirm that DUSP1 expression is associated with CDDP-resistance, DUSP1 was overexpressed using the addition of DUSP1-cDNA (Fig. 2A; protein level) in SGC996 and GBC-SD cells, and then these cells were treated with CDDP or 5-FU. An MTT assay was applied to analyze the survival rate of these cells. Furthermore, single staining for PI was performed to evaluate the cytotoxicity of these cells subsequent to CDDP treatment. SGC996 cells with DUSP1 overexpression (SGC996 OE) were less sensitive to CDDP and 5-FU treatment compared with the control cells (SGC996-vector) (Fig. 2A). Fewer PI positive cells were
A

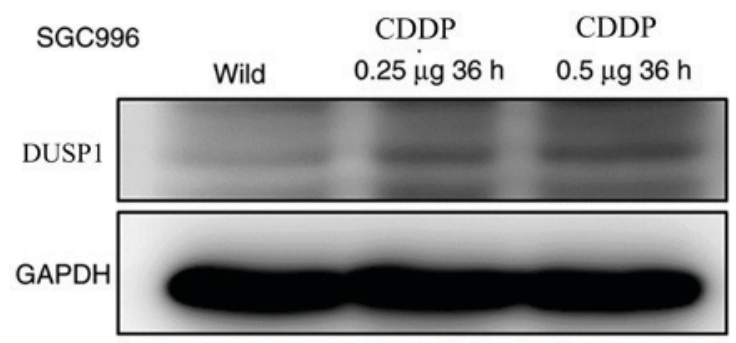

B

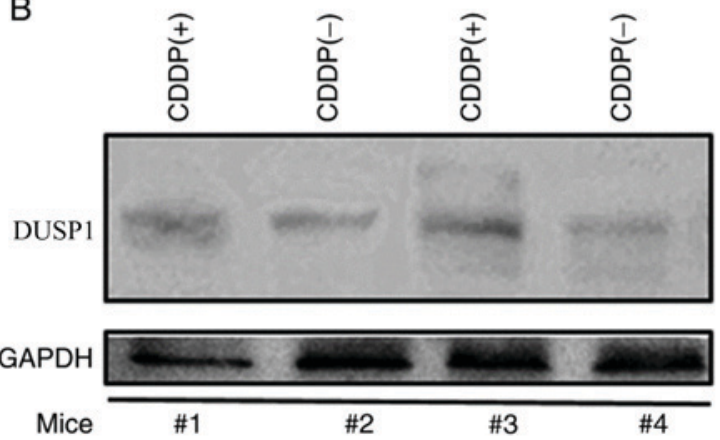

Figure 1. DUSP1 was markedly increased in CDDP-resistant SGC996 cells and CDDP-treated tumor types in vivo. (A) Western blots performed using a DUSP1 antibody revealed elevated DUSP1 expression in established CDDP-resistant SGC996 cells compared with normal (wild) SGC996 cells. (B) Mice with subcutaneously injected SGC996 cells were sacrificed after 1 week of CDDP ( $4 \mu \mathrm{g} /$ day) treatment, the tumor protein was extracted and DUSP1 expression was detected to be higher in the treatment group compared with the control group. DUSP, dual-specificity phosphatase; CDDP, cisplatin; CDDP(-), non-cisplatin treatment; $\mathrm{CDDP}(+)$, cisplatin treatment.

observed in SGC996 OE cells compared with the control cells, and SGC996 OE cells presented a significantly higher cell viability compared with the control cells $(\mathrm{P}<0.05)$ which indicated a lower apoptosis rate (Fig. 2B). Similarly, GBC-SD DUSP1 overexpressing (GBC-SD OE) cells were less sensitive to CDDP and 5-FU treatment compared with the control cells (Fig. 2C). Additionally, there was a significantly higher cell viability of GBC-SD OE cells compared with the control cells $(\mathrm{P}<0.01$; Fig. 2D). Altogether, the evidence indicates that DUSP1 enhances chemoresistance in GBC.

DUSP1 overexpression resulted in decreased p38 MAPK apoptosis and decreased DNA damage. DNA damage is a major factor resulting in normal cell death and the DNA damage response is crucial for cell survival. Once DNA damage occurs, the foci of phosphorylated $\mathrm{H} 2 \mathrm{AX}$ $(\gamma \mathrm{H} 2 \mathrm{AX})$ will be rapidly formed in order to recruit repair factors $(32,33)$. Thus, $\gamma \mathrm{H} 2 \mathrm{AX}$ staining usually serves as a marker for DNA damage in previous studies (34). DNA damage in SGC996-OE cells was detected to be significantly decreased by immunofluorescent staining compared with SGC996-Vector cells $(\mathrm{P}<0.01$; Fig. 3A). This was further verified using a western blot assay (Fig. 3B). CDDP-induced p-p38 MAPK additionally decreased in GBC-SD-OE cells compared with the control cells, which resulted in reduced CDDP-induced apoptosis, evidenced by the relatively 
A

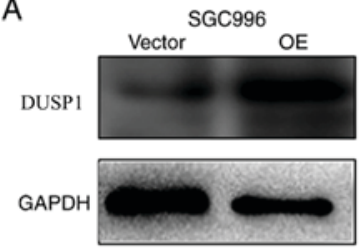

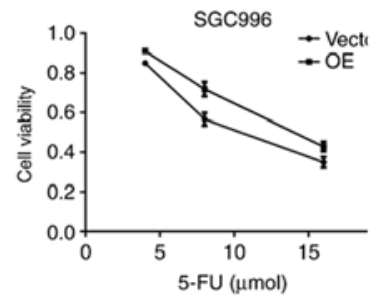

C
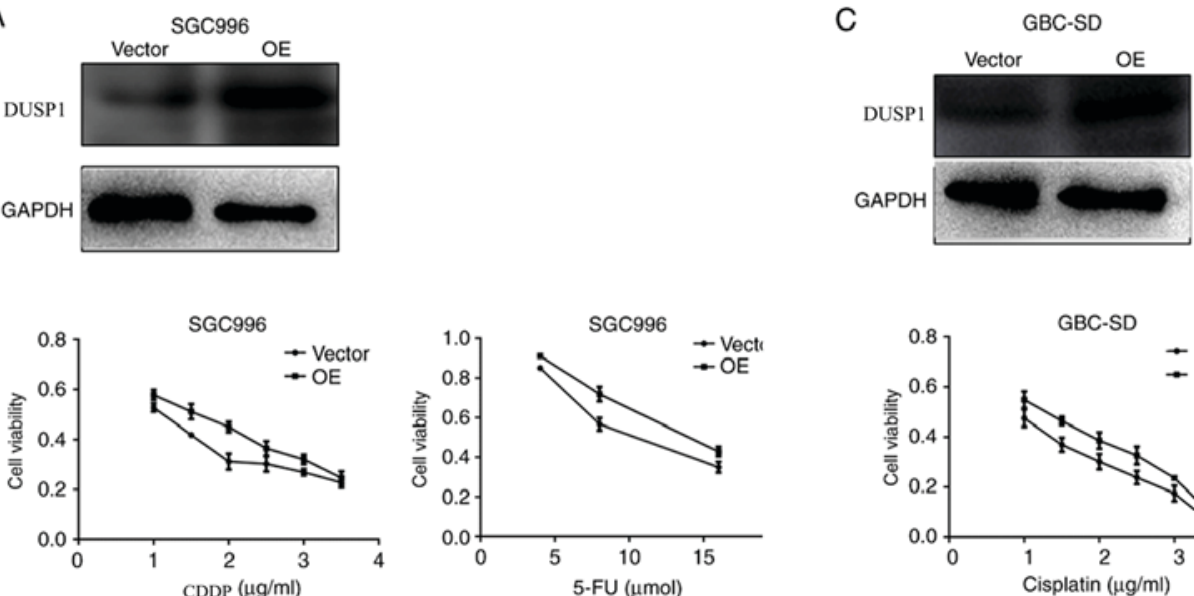

B
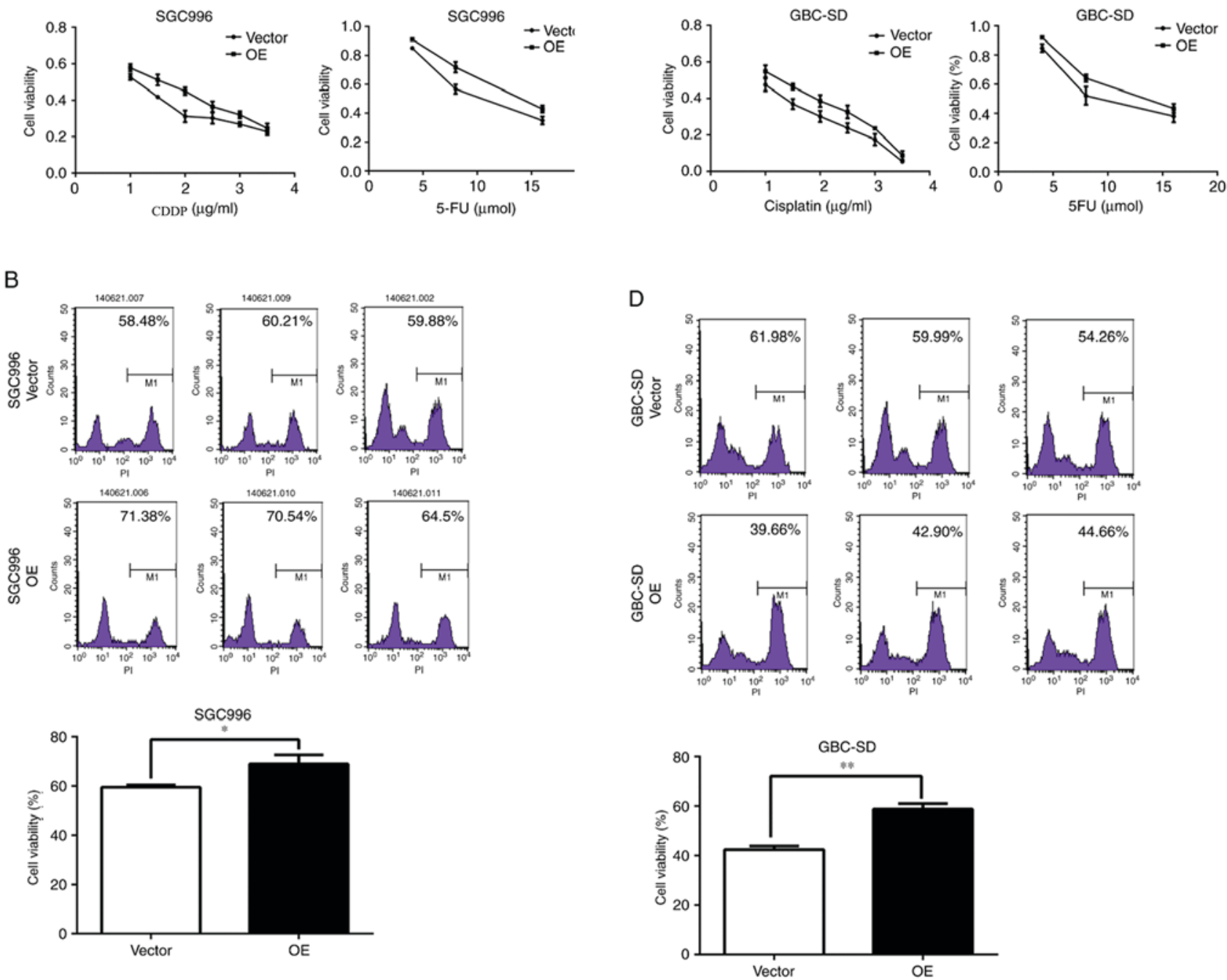

Figure 2. DUSP1 may decrease CDDP and 5-FU chemotherapy efficiency in GBC cells. (A) SGC996 cells that were DUSP1 OE or normal (vector) were seeded in 96-well plates, and treated with different concentrations of CDDP $(1,1.5,2,2.5,3$ and $3.5 \mu \mathrm{g} / \mathrm{ml})$ or 5-FU (4, 8 and $16 \mu$ mol) for $48 \mathrm{~h}$, and then MTT assays for cell viability were performed. (B) SGC996 cells that were DUSP1 OE or normal (vector) were seeded in 6-well plates, treated with CDDP for $48 \mathrm{~h}$, harvested and washed twice with PBS, stained with PI in the binding buffer, and detected using flow cytometry. (C) GBC-SD cells that were DUSP1 OE or normal (vector) were seeded in 96-well plates, and treated with different concentrations of CDDP $(1,1.5,2,2.5,3$ and $3.5 \mu \mathrm{g} / \mathrm{ml})$ or 5 -FU $(4,8 \mathrm{and} 16 \mu \mathrm{mol})$ for $48 \mathrm{~h}$, and then MTT cell viability assays were performed. (D) GBC-SD cells that were DUSP1 OE or normal (vector) were seeded in 6-well plates, treated with CDDP for $48 \mathrm{~h}$, harvested and washed twice with PBS, stained with PI in the binding buffer, and detected using flow cytometry. "P< $<0.05$ and ${ }^{* *} \mathrm{P}<0.01$ with comparisons shown by lines. DUSP, dual-specificity phosphatase; CDDP, cisplatin; GBC, gallbladder cancer; OE, overexpression; 5-FU, fluorouracil; PI, propidium iodide.

decreased expression of cleaved PARP and cleaved caspase 3 in GBC-SD-OE cells compared with the control cells (Fig. 3B).

\section{Discussion}

DUSP1 is induced in response to oxidative stress, hypoxia, and a number of other factors including nutritional deprivation by the regulation of tumor protein p53, transcription factor E2F1, c-Jun and activating transcription factor
$2(15,35,36)$. An increased expression of DUSP1 was detected in PDAC following gemcitabine treatment and served a function in the chemoresistance of gemcitabine (31). Similarly, the elevated expression of DUSP1 in CDDP-resistant GBC cells was detected in the present study. CDDP, as a normal chemotherapy drug, triggers DNA damage response and p38 MAPK activation, resulting in cell death $(13,37)$. A number of studies have indicated that CDDP activates p38 MAPK, thereby inducing apoptosis in cells and that the inhibition of p38 MAPK activation may be associated with 

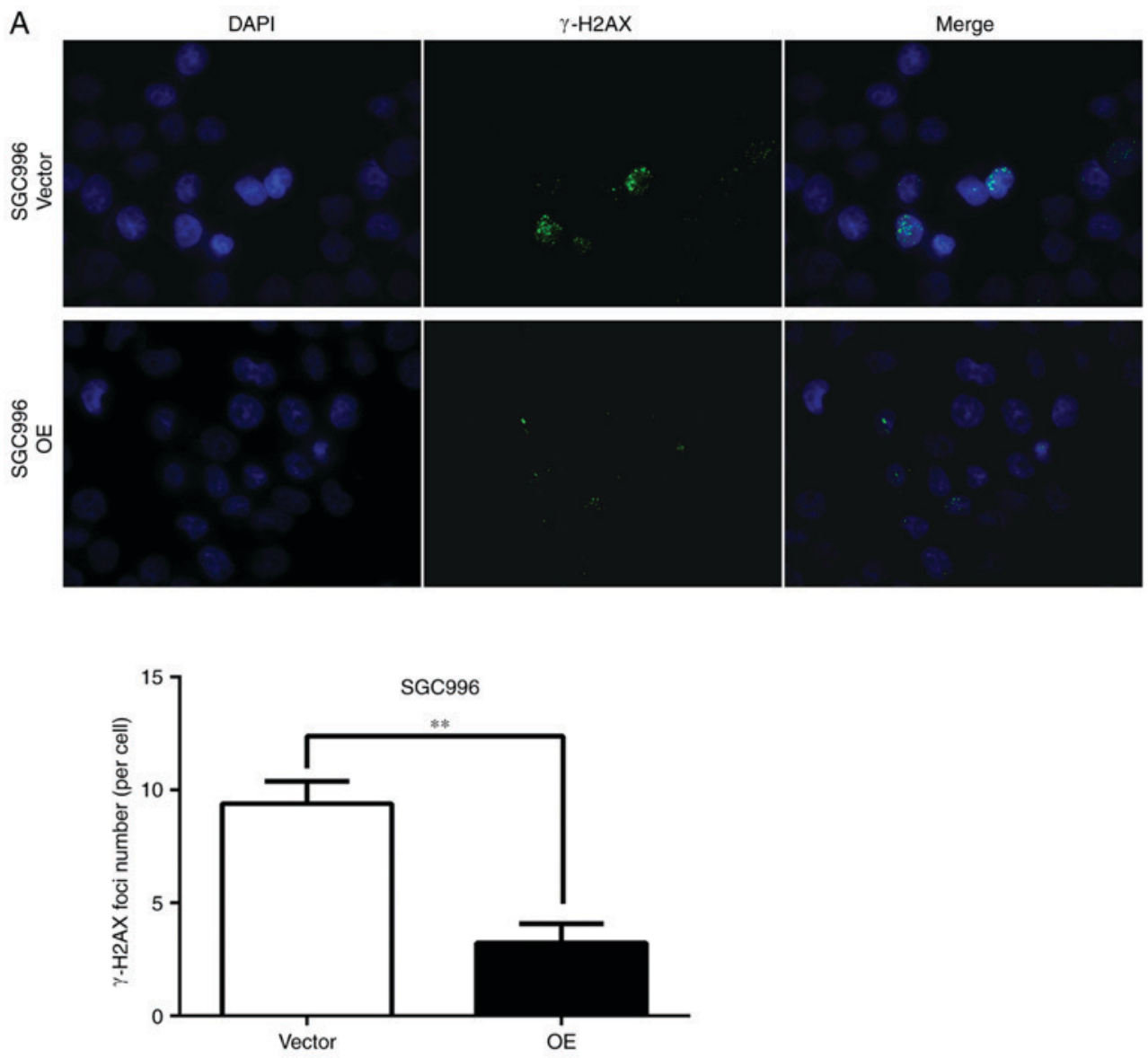

B

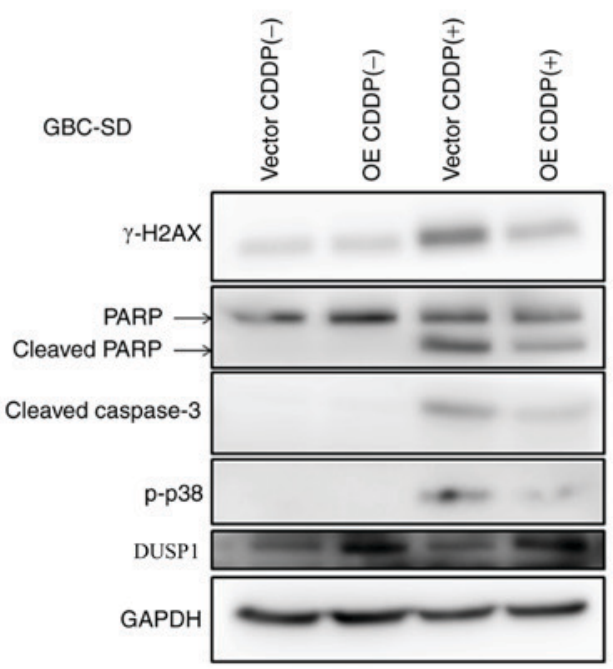

Figure 3. DUSP1 decreases p-p38 and $\gamma \mathrm{H} 2 \mathrm{AX}$ protein expression levels. Cells were treated with $4 \mu \mathrm{g} / \mathrm{ml} \mathrm{CDDP}$ for $24 \mathrm{~h}$. (A) Immunocytochemical detection of $\gamma \mathrm{H} 2 \mathrm{AX}$-foci revealed a significant decrease DNA double-strand breaks in SGC996 OE cells compared with the control cells (vector). (B) Western blots revealed that CDDP treatment increased cleaved PARP, cleaved caspase 3, p-p38 and $\gamma \mathrm{H} 2 \mathrm{AX}$ in GBC-SD cells, and that in comparison an overexpression of DUSP1 decreased the levels of these proteins. ${ }^{* *} \mathrm{P}<0.01$ with comparisons shown by lines. OE, overexpression; $\gamma \mathrm{H} 2 \mathrm{AX}$, phosphorylated-H2A histone family, member X; CDDP, cisplatin; CDDP(-), non-cisplatin treatment; CDDP(+), cisplatin treatment; PARP, poly (ADP-ribose) polymerase; p-, phosphorylated; DUSP, dual-specificity phosphatase.

CDDP-resistance in ovarian cancer (38-40). Additionally, CDDP inducing DNA cross links and DSBs contributes to cancer treatment $(41,42)$. However, the effectiveness of CDDP in various cancer types such as pancreatic, breast and lung cancer (43-45) is hampered by the development of drug resistance over time.
In the present study, DUSP1 additionally enhanced chemoresistance in GBC. Overexpressing DUSP1 may attenuate the activation of p38 MAPK, thereby resulting in a lower apoptotic rate as evidenced by the decreased cleaved PARP expression and activated caspase 3 protein expression. Furthermore, fewer $\gamma \mathrm{H} 2 \mathrm{AX}$ foci were formed in the SGC996-OE cells compared 
with the control cells. In this sense, DUSP1 may serve a function in reducing DNA damage and protecting GBC from cell death. Targeting DUSP1 may improve the efficiency of chemotherapy in GBC.

To conclude, the results of the present study demonstrated that DUSP1 may function through the downregulation of $\mathrm{p} 38$ MAPK and DNA damage to influence the efficiency of GBC chemotherapy. Previous finding have revealed that DUSP1 may additionally function through JNK-MAPK signaling to reduce the cytotoxicity caused by gemcitabine in pancreatic cancer (31). However, gemcitabine is widely applied in GBC treatment (46). Novel small molecules may be developed in the near future that target DUSP1 in order to suppress GBC progression more effectively.

\section{Acknowledgements}

Not applicable.

\section{Funding}

No funding was received.

\section{Availability of data and materials}

The data generated in the present study are available on reasonable request from the corresponding author.

\section{Authors' contributions}

JF and YW contributed to the research design and operation, data analysis and manuscript preparation. The other authors contributed to the research. ZY, FG, MY and QL contributed to the cell research. JL, ZW and YX contributed to the animal research.

\section{Ethics approval and consent to participate}

Ethical approval was provided by the Institutional Animal Care and Use Committee of Zhejiang Medical College, Zhejiang University (Zhejiang, China) for all animal experiments.

\section{Consent for publication}

Not applicable.

\section{Competing interests}

The authors declare that they have no competing interests.

\section{References}

1. Lazcano-Ponce EC, Miquel JF, Muñoz N, Herrero R, Ferrecio C, Wistuba II, Alonso de Ruiz P, Aristi Urista G and Nervi F: Epidemiology and molecular pathology of gallbladder cancer. CA Cancer J Clin 51: 349-364, 2001.

2. Gourgiotis S, Kocher HM, Solaini L, Yarollahi A, Tsiambas E and Salemis NS: Gallbladder cancer. Am J Surg 196: 252-264, 2008.

3. Malik IA, Aziz Z, Zaidi SH and Sethuraman G: Gemcitabine and Cisplatin is a highly effective combination chemotherapy in patients with advanced cancer of the gallbladder. Am J Clin Oncol 26: 174-177, 2003.
4. Chatni SS, Sainani RS, Mehta SA and Mohandas KM: Infusion chemotherapy with cisplatinum and fluorouracil in the treatment of locally-advanced and metastatic gallbladder cancer. J Cancer Res Ther 4: 151-155, 2008.

5. Reddy N and Czuczman MS: Enhancing activity and overcoming chemoresistance in hematologic malignancies with bortezomib: Preclinical mechanistic studies. Ann Oncol 21: 1756-1764, 2010

6. Peiffert D, Seitz JF, Rougier P, François E, Cvitkovic F, Mirabel X, Nasca S, Ducreux M, Hannoun-Levi JM, Lusinchi A, et al: Preliminary results of a phase II study of high-dose radiation therapy and neoadjuvant plus concomitant 5-fluorouracil with CDDP chemotherapy for patients with anal canal cancer: A French cooperative study. Ann Oncol 8: 575-581, 1997.

7. Doval DC, Sekhon JS, Gupta SK, Fuloria J, Shukla VK, Gupta S and Awasthy BS: A phase II study of gemcitabine and cisplatin in chemotherapy-naive, unresectable gall bladder cancer. Br J Cancer 90: 1516-1520, 2004.

8. Bleiberg H, Conroy T, Paillot B, Lacave AJ, Blijham G, Jacob JH, Bedenne L, Namer M, De Besi P, Gay F, et al: Randomised phase II study of cisplatin and 5-fluorouracil (5-FU) versus cisplatin alone in advanced squamous cell oesophageal cancer. Eur J Cancer 33: 1216-1220, 1997.

9. Sohn BS, Yuh YJ, Kim KH, Jeon TJ, Kim NS and Kim SR: Phase II trial of combination chemotherapy with gemcitabine, 5 -fluorouracil and cisplatin for advanced cancers of the bile duct, gallbladder, and ampulla of Vater. Tumori 99: 139-144, 2013.

10. Roos WP and Kaina B: DNA damage-induced cell death: From specific DNA lesions to the DNA damage response and apoptosis. Cancer Lett 332: 237-248, 2013.

11. Roos WP and Kaina B: DNA damage-induced cell death by apoptosis. Trends Mol Med 12: 440-450, 2006.

12. Jordan P and Carmo-Fonseca M: Molecular mechanisms involved in cisplatin cytotoxicity. Cell Mol Life Sci 57: 1229-1235, 2000.

13. Kartalou M and Essigmann JM: Mechanisms of resistance to cisplatin. Mutat Res 478: 23-43, 2001.

14. Gosland M, Lum B, Schimmelpfennig J, Baker J and Doukas M: Insights into mechanisms of cisplatin resistance and potential for its clinical reversal. Pharmacotherapy 16: 16-39, 1996.

15. Liu YX, Wang J, Guo J, Wu J, Lieberman HB and Yin Y: DUSP1 is controlled by p53 during the cellular response to oxidative stress. Mol Cancer Res 6: 624-633, 2008.

16. Bang YJ, Kwon JH, Kang SH, Kim JW and Yang YC: Increased MAPK activity and MKP-1 overexpression in human gastric adenocarcinoma. Biochem Biophys Res Commun 250: 43-47, 1998.

17. Wang HY, Cheng $\mathrm{Z}$ and Malbon CC: Overexpression of mitogen-activated protein kinase phosphatases MKP1, MKP2 in human breast cancer. Cancer Lett 191: 229-237, 2003.

18. Vicent S, Garayoa M, López-Picazo JM, Lozano MD, Toledo G, Thunnissen FB, Manzano RG and Montuenga LM: Mitogen-activated protein kinase phosphatase-1 is overexpressed in non-small cell lung cancer and is an independent predictor of outcome in patients. Clin Cancer Res 10: 3639-3649, 2004.

19. Denkert C, Schmitt WD, Berger S, Reles A, Pest S, Siegert A, Lichtenegger W, Dietel M and Hauptmann S: Expression of mitogen-activated protein kinase phosphatase-1 (MKP-1) in primary human ovarian carcinoma. Int J Cancer 102: 507-513, 2002.

20. Liu C, Shi Y, Du Y, Ning X, Liu N, Huang D, Liang J, Xue Y and Fan D: Dual-specificity phosphatase DUSP1 protects overactivation of hypoxia-inducible factor 1 through inactivating ERK MAPK. Exp Cell Res 309: 410-418, 2005.

21. Cortes-Sempere M, Chattopadhyay S, Rovira A, Rodriguez-Fanjul V, Belda-Iniesta C, Tapia M, Cejas P Machado-Pinilla R, Manguan-García C, Sánchez-Pérez I, et al: MKP1 repression is required for the chemosensitizing effects of NF-kappaB and PI3K inhibitors to cisplatin in non-small cell lung cancer. Cancer Lett 286: 206-216, 2009.

22. Small GW, Shi YY, Higgins LS and Orlowski RZ: Mitogen-activated protein kinase phosphatase-1 is a mediator of breast cancer chemoresistance. Cancer Res 67: 4459-4466, 2007.

23. Sánchez-Pérez I, Martínez-Gomariz M, Williams D, Keyse SM and Perona R: CL100/MKP-1 modulates JNK activation and apoptosis in response to cisplatin. Oncogene 19: 5142-5152, 2000.

24. Wang Z, Zhou JY, Kanakapalli D, Buck S, Wu GS and Ravindranath Y: High level of mitogen-activated protein kinase phosphatase-1 expression is associated with cisplatin resistance in osteosarcoma. Pediatr Blood Cancer 51: 754-759, 2008. 
25. Livak KJ and Schmittgen TD: Analysis of relative gene expression data using real-time quantitative PCR and the 2(-Delta Delta C(T)) method. Methods 25: 402-408, 2001.

26. Norton JN, Reynolds RP, Chan C, Valdivia RH and Staats HF: Assessing the satisfaction and burden within an academic anima care and use program. FASEB J 31: 3913-3921, 2017.

27. Lin SJ, Lee SO, Lee YF, Miyamoto H, Yang DR, Li G and Chang C: TR4 nuclear receptor functions as a tumor suppressor for prostate tumorigenesis via modulation of DNA damage/repair system. Carcinogenesis 35: 1399-1406, 2014.

28. Cai BL, Xu XF, Fu SM, Shen LL, Zhang J, Guan SM and Wu JZ: Nuclear translocation of MRP1 contributes to multidrug resistance of mucoepidermoid carcinoma. Oral Oncol 47: 1134-1140, 2011.

29. Stein U, Lage H, Jordan A, Walther W, Bates SE, Litman T, Hohenberger P and Dietel M: Impact of BCRP/MXR, MRP1 and MDR1/P-Glycoprotein on thermoresistant variants of atypical and classical multidrug resistant cancer cells. Int J Cancer 97: 751-760, 2002

30. Tong Y, Li QG, Xing TY, Zhang M, Zhang JJ and Xia Q: HIF1 regulates WSB-1 expression to promote hypoxia-induced chemoresistance in hepatocellular carcinoma cells. FEBS Lett 587: 2530-2535, 2013

31. Liu F, Gore AJ, Wilson JL and Korc M: DUSP1 is a novel target for enhancing pancreatic cancer cell sensitivity to gemcitabine. PLoS One 9: e84982, 2014.

32. Redon C, Pilch D, Rogakou E, Sedelnikova O, Newrock K and Bonner W: Histone H2A variants H2AX and H2AZ. Curr Opin Genet Dev 12: 162-169, 2002.

33. Celeste A, Petersen S, Romanienko PJ, Fernandez-Capetillo O, Chen HT, Sedelnikova OA, Reina-San-Martin B, Coppola V, Meffre E, Difilippantonio MJ, et al: Genomic instability in mice lacking histone H2AX. Science 296: 922-927, 2002.

34. Svetlova MP, Solovjeva LV and Tomilin NV: Mechanism of elimination of phosphorylated histone $\mathrm{H} 2 \mathrm{AX}$ from chromatin after repair of DNA double-strand breaks. Mutat Res 685: 54-60, 2010.

35. Wang J, Yin DP, Liu YX, Baer R and Yin Y: Dual specificity phosphatase $1 /$ CL100 is a direct transcriptional target of E2F-1 in the apoptotic response to oxidative stress. Cancer Res 67 6737-6744, 2007.

36. Breitwieser W, Lyons S, Flenniken AM, Ashton G, Bruder G, Willington M, Lacaud G, Kouskoff V and Jones N: Feedback regulation of p38 activity via ATF2 is essential for survival of embryonic liver cells. Genes Dev 21: 2069-2082, 2007.
37. Hernández Losa J, Parada Cobo C, Guinea Viniegra J, Sánchez-ArevaloLobo VJ,Ramón y CajalS and Sánchez-PrietoR: Role of the p38 MAPK pathway in cisplatin-based therapy. Oncogene 22: 3998-4006, 2003.

38. Weir NM, Selvendiran K, Kutala VK, Tong L, Vishwanath S, Rajaram M,Tridandapani S, Anant S and Kuppusamy P: Curcumin induces $\mathrm{G} 2 / \mathrm{M}$ arrest and apoptosis in cisplatin-resistant human ovarian cancer cells by modulating Akt and p38 MAPK. Cancer Biol Ther 6: 178-184, 2007.

39. Mansouri A, Ridgway LD, Korapati AL, Zhang Q, Tian L, Wang Y, Siddik ZH, Mills GB and Claret FX: Sustained activation of JNK/p38 MAPK pathways in response to cisplatin leads to Fas ligand induction and cell death in ovarian carcinoma cells. J Biol Chem 278: 19245-19256, 2003.

40. Yuan ZQ, Feldman RI, Sussman GE, Coppola D, Nicosia SV and Cheng JQ: AKT2 inhibition of cisplatin-induced JNK/p38 and Bax activation by phosphorylation of ASK1: Implication of AKT2 in chemoresistance. J Biol Chem 278: 23432-23440, 2003.

41. Jamieson ER and Lippard SJ: Structure, recognition, and processing of cisplatin-DNA adducts. Chem Rev 99: 2467-2498, 1999.

42. Gong JG, Costanzo A, Yang HQ, Melino G, Kaelin WG Jr, Levrero $\mathrm{M}$ and Wang JY: The tyrosine kinase c-Abl regulates p73 in apoptotic response to cisplatin-induced DNA damage. Nature 399: 806-809, 1999

43. Danilov AV, Neupane D, Nagaraja AS, Feofanova EV, Humphries LA,DiRenzoJ andKorc M:DeltaNp63alpha-mediated induction of epidermal growth factor receptor promotes pancreatic cancer cell growth and chemoresistance, PLoS One 6: e26815, 2011.

44. Lapensee EW, Tuttle TR, Fox SR and Ben-Jonathan N: Bisphenol $\mathrm{A}$ at low nanomolar doses confers chemoresistance in estrogen receptor-alpha-positive and -negative breast cancer cells. Environ Health Perspect 117: 175-180, 2009.

45. Sève $P$ and Dumontet $C$ : Chemoresistance in non-small cell lung cancer. Curr Med Chem Anticancer Agents 5: 73-88, 2005.

46. Nakamura M, Nakashima H, Abe T, Ensako T, Yoshida K and Hino K: Gemcitabine-based adjuvant chemotherapy for patients with advanced gallbladder cancer. Anticancer Res 34: 3125-3129, 2014. 